\title{
MODEL BAHAN AJAR MULOK BERBASIS CERITA RAKYAT UNTUK PENDIDIKAN KARAKTER DI SD
}

\author{
Abdul Muktadir \\ FKIP Universitas Bengkulu \\ email: abdulmuktadir755@yahoo.co.id
}

\begin{abstract}
Abstrak
Penelitian ini bertujuan untuk merancang model bahan ajar muatan lokal (mulok) berbasis cerita rakyat untuk pendidikan karakter. Penelitian ini merupakan penelitian pengembangan model Borg dan Gall. Tahapan yang dilakukan meliputi studi pendahuluan, penyusunan draft, penilaian pakar dan pengguna, dan uji lapangan. Penilaian dari pakar dan pengguna menunjukkan bahwa bahan ajar mulok berbasis cerita rakyat memenuhi kriteria kelayakan. Penilaian kelayakan difokuskan pada empat komponen, yaitu isi, kebahasaan, penyajian, dan kegrafikan, dengan persentase rata-rata sebesar 78,91\%. Efektivitas didasarkan pada nilai hasil uji coba lapangan dengan mengacu pada kriteria ketuntasan minimal (KKM) mata pelajaran mulok, yakni 65. Nilai hasil uji coba lapangan mencapai rata-rata 71,74 dengan ketuntasan sekolah secara klasikal. Capaian nilai ratarata siswa yang lebih tinggi dari nilai KKM menunjukkan bahwa bahan ajar yang dikembangkan efektif sehingga layak untuk digunakan dalam proses pembelajaran mulok.
\end{abstract}

Kata kunci: efektivitas, bahan ajar mulok, cerita rakyat, pendidikan karakter

\section{A MODEL OF LOCAL CONTENT LEARNING MATERIALS BASED ON FOLKLORES FOR CHARACTER EDUCATION AT ELEMENTARY SCHOOLS}

\begin{abstract}
This study aimed to design a model of local content learning materials based on folklores for character education. This was a research and development study using Borg and Gall's model. The steps were a preliminary study, draft designing, expert and user assessments, and a field tryout. The results of expert and user assessments showed that the developed materials satisfied the appropriateness criteria. The appropriateness assessments were focused on four components, namely content, language, presentation, and graphics, of which the average was $78.91 \%$. The effectiveness was based on the mean score from the field tryout by referring to the minimum mastery criterion (MMC) for a local content subject, namely 65 . The result of the field tryout was indicated by a mean score of 71.74 for the school mastery as a whole. The students' average achievement which was higher than the MMC indicated that the learning materials were effective so that they were appropriate for use in the local content learning process.
\end{abstract}

Keywords: effectiveness, local content learning materials, folklores, character education 


\section{PENDAHULUAN}

Efektivitas bahan ajar sangat tergantung kepada kualitas isi dan tampilan bahan ajar, tanpa mengabaikan kebutuhan pengguna dalam merancang bahan ajar tersebut. Sadiman (2008: 28) mengatakan karakteristik anak SD berada pada tahap operasional konkrit. Pembelajaran harus dikemas dalam media konkrit. Penggunaan ilustrasi sebagai sarana penyampai materi dapat dijadikan sebagai media pembelajaran, umpamanya bahan ajar cetak sebagai buku ajar. Ilustrasi dalam bahan ajar sangat penting, berfungsi untuk menarik perhatian, memperjelas materi, menghiasi fakta yang mungkin akan cepat dilupakan apabila tidak di grafiskan.

Kualitas pemahaman siswa selain ditentukan keberadaan ilustrasi dalam bahan ajar adalah materi bahan ajar itu sendiri. Abidin (2012: 222) menyatakan dengan adanya kesamaan budaya dengan yang diajarkan (bahan ajar) guru siswa akan lebih cepat memahaminya. Gopal (2005) dalam hasil penelitiannya menyebutkan bahwa pembelajaran baru terjadi ketika siswa memahami apa yang dipelajarinya dari perspektif budaya mereka sendiri, sehingga pengetahuan dan kearifan lokal sangat perlu diintegrasikan dalam pendidikan formal.

Kearifan lokal yang akan diintegrasikan dalam pendidikan melalui mata pelajaran Muatan Lokal (Mapel Mulok) adalah cerita rakyat dalam. Tujuan pembelajaran Mulok adalah: a) mengenal dan mencintai lingkungan alam, sosial, budaya, dan spiritual di daerahnya; dan b) melestarikan dan mengembangkan keunggulan dan kearifan daerah yang berguna bagi diri dan lingkungannya dalam rangka menunjang pembangunan nasional (Permen- dikbud Nomor 79 Tahun 2014). Salah satu penekanan tujuan dalam permen ini untuk mengenal, mencintai, melestarikan, dan mengembangkan keunggulan daerah. Lingkup keunggulan daerah dapat berupa cerita rakyat.

Cerita rakyat bagian dari folklor. Folklor memiliki fungsi untuk pendidikan karakter. Pendidikan karakter menurut Endaswara (2013: 1) identik dengan membentuk sikap dan perilaku mulia yang sangat dibutuhkan dalam perkembangan anak khususnya. Pendidikan karakter akan meningkatkan kognitif, afektif, dan perilaku manusia yang lebih bermoral. Selanjutnya dalam Kemendikbud Dirjendikdasmen (2015: 9) penilaian sikap meliputi: 1) jujur, 2) disiplin, 3) tanggung jawab, 4) santun, 5) peduli, dan 6) percaya diri. Namun dalam jurnal penelitian Muktadir, dkk. (2014) disimpulkan bahwa sikap-sikap yang menjadi nilai karakter belum dianalisis dalam mapel Mulok.

Berdasarkan pengamatan keberadaan konteks kelokalan dalam pembelajaran masih jarang dimanfaatkan dalam bahan ajar. Selain itu dari segi tampilan buku ajar yang digunakan minim ilustrasi. Tampilan buku dapat memberi kesan pertama untuk isi buku. Pada dasarnya siswa akan lebih tertarik teradap bahan ajar yang kaya ilustrasi dibanding penggunaan teks yang dominan.

Dari uraian yang dikemukakan penelitian ini bertujuan untuk merancang bahan ajar mapel Mulok berbasis cerita rakyat yang efektif untuk pendidikan karakter yang efektif di SD. Bahan ajar yang dikembangkan berdasarkan komponen evaluasi bahan ajar dari Depdiknas (2008: 28) yakni: 1) Komponen kelayakan isi, 2) Komponen kebahasaan, 3) Komponen 
penyajian, dan 4) Komponen kegrafikan. Efektif dalam hal ini mengacu indikator belajar yang tepat untuk mengukur hasil pembelajaran.

\section{METODE}

Penelitian ini menggunakan metode penelitian pengembangan langkah-langkah Borg dan Gall (1981:775) meliputi 10 langkah untuk menghasilkan model bahan ajar Mulok berbasis ceita rakyat untuk pendidikan karakter. Tahap awal merancang bahan ajar menurut Jolly dan Rod dalam Tomlinson (1998: 98-99) adalah identifikasi kebutuhan.

Untuk mendapatkan data penelitian digunakan instrumen. Sumber data adalah bahan ajar dan hasil wawancara kepada guru dan siswa. Data diperoleh dari studi dokumen, observasi dan wawancara. Data dianalisis melalui tahap: a) reduksi data, b) display data, c) menyimpulkan dan memverifikasi, dan persentase. Validitas dan realibilitas diuji melalui tahap: a) kredibilitas (validitas internal) melalui perpanjangan masa observasi, pengamatan, triangulasi teknik dan pakar, member check, b) reliabilitas dilakukan dengan membandingkan antarpeneliti, triangulasi, dan member check.

\section{HASIL DAN PEMBAHASAN \\ Hasil Penelitian Pengembangan}

Bahan ajar yang dikembangkan adalah Bahan ajar Mulok berbasis cerita rakyat Bengkulu untuk pendidikan karakter di SD. Kompetensi yang akan dikembangkan dalam bahan ajar adalah: 1) menentukan dan menjelaskan alasan menentukan tema cerita, 2) menjelaskan kilasan peristiwa dari cerita, 3) menyebutkan nama tokoh dan karakter, 4) menjelaskan sikap tokoh terhadap tokoh lain, 5) membandingkan pengalaman tokoh dan pengalaman siswa, 6) menjelaskan perilaku tokoh yang pantas ditiru dan perilaku yang tidak pantas ditiru, 7) meringkas cerita, 8) menulis kalimatkalimat pokok cerita dalam bahasa rejang, 9) menulis kata sapaan, kata benda, kata sifat, kata bilangan dalam aksara rejang, dan 10) menulis nilai-nilai karakter dalam aksara Rejang. Kompetensi dirancang tersebut dikemas dalam stuktur bahan ajar mancakup kemampuan: 1) menyimak, 2) membaca, 3) berbicara, 4) menulis, dan 5) latihan-latihan. Latihan-latihan diawali dengan kata-kata mengajak, umpamanya: Ayo Menyimak! Mari Berlatih!

Data-data penelitian disajikan berdasarkan: 1) analisis data penyempurnaan produk bahan ajar, 2) evaluasi produk bahan ajar mencakup: a) komponen kelayakan isi, b) komponen kebahasaan, c) komponen penyajian, dan 4) komponen kegrafikan, dan 3) keefektivan produk bahan ajar komponen evaluasi.

Pertama, uji coba produk berdasarkan hasil uji coba produk bahan ajar Mulok diperoleh rata-rata 57.5 dari skala empat (4) dan hasil $75.65 \%$. Dari nilai rata-rata dan hasil ini dinyatakan kriteria bahan ajar sangat valid. Nilai rata-rata dan persentase mencakup aspek penilaian bahan ajar yakni: a) komponen kelayakan isi, b) komponen kebahasaan, c) komponen penyajian, dan d) komponen kegrafikan.

Kedua, hasil rata-rata dari komponen kelayakan isi adalah 17 dan persentase 70 menyimpulkan komponen kelayakan isi bahan ajar valid. Dari hasil uji coba produk bahan ajar ada masukan dari pengguna dan validator yakni: KD untuk berpikir tinggkat tinggi sebaiknya lebih dominan, karater tokoh cerita diperkaya terutama 
yang sejalan dengan penguatan pendidikan karakter, tema cerita dipilih yang mengemas berbagai persoalan hidup dan berbagai karakter tokoh, tema cerita dipilih yang jelas sebab akibatnya. Permasalahan dalam cerita dipilih yang membuat anak berpikir.

Ketiga, hasil rata-rata dari komponen kebahaaan adalah 13 dan persentase 81.25 menyimpulkan komponen kebahasaan bahan ajar sangat valid. Dari hasil uji coba produk bahan ajar ada masukan dari pengguna dan validator yakni: keterbacaan dalam bahan ajar hendaknya disajikan dengan bahasa menarik, kosa kata daerah diganti dengan kosa kata bahasa Indonesia, tidak menimbulkan makna ganda, kata ganti dan kata sambungyang tidak perlu dihilangkan, menggunakan kalimat efektif dan lazim dalam komunikasi tulis bahasa Indonesia, kaidah bahasa Indonesia pada bahan ajar harus menggunakan tata bahasa yang benar.

Keempat, hasil rata-rata dari komponen penyajian adalah 16 dan persentase 80 menyimpulkan komponen kebahasaan bahan ajar sangat valid. Dari hasil uji coba produk bahan ajar ada masukan dari pengguna dan validator yakni: struktur materi sesuai dengan komponen keterampilan berbahasa, setiap cerita lengkapi dengan gambar yang memperjelas bagian cerita, setiap sub topik lengkapi latihan-latihan, perintah setiap tugas susun jelas, cerita yang dirujuk jadi bacaan sebaiknya cerita dari daerah setempat, cerita harus jelas sumbernya, tema-tema cerita lebih bervariasi agar karakter tokoh yang ditampilkan dapat memperkaya nilai-nilai karakter pembaca, tema cerita dipilih tema yang lebih memotivasi pembaca agar menumbuhkan pemikiran kritis, kreatif dan inovatif, urutan materi supaya lebih konsis- ten dari yang materi mudah ke materi yang sulit.

Keempat, hasil rata-rata dari komponen kegrafikan adalah 13.5 dan persentase 84.37 menyimpulkan komponen kebahasaan bahan ajar sangat valid. Dari hasil uji coba produk bahan ajar ada masukan dari pengguna dan validator yakni: ukuran buku gunakan kertas A4, penggunaan font (jenis dan ukuran) sebaiknya bervariasi umpamanya font untuk judul, sub judul dan materi ukuran 12-14, dalam satu halaman maksimal empat warna dan warna sebaiknya memberi makna, gambar sebaiknya berada dalam teks.

Kelima, efektivitas bahan ajar Mulok berbasis cerita rakyat untuk pendidikan karakter di SD diperoleh dari nilai hasil uji coba lapangan yang dasarkan dengan kriteria ketuntasan minimal (KKM) mata pelajaran Mulok yakni 65. Nilai hasil pembelajaran menggunakan bahan ajar Mulok berbasis cerita rakyat untuk pendidikan karakter pada uji coba lapangan mencapai nilai rata-rata 71.74 dengan ketuntasan sekolah klasikal mata pelajaran Mulok adalah 65. Dengan demikian dapat dikatakan bahan nilai rata-rata siswa adalah 71.74 ini lebih tinggi dari nilai KKM 65, dengan demikian efektivitas bahan ajar tercapai.

\section{Pembahasan}

Kevalidan bahan ajar Mulok terkait dengan proses perancangan bahan ajar yang dilakukan mulai dari tahap: 1) perencanaan, 2) produk, dan 3) evaluasi. Tahap evaluasi bahan ajar Mulok dilakukan melalui tiga tahap yang menentukan kevalidan bahan ajar. Evaluasi sebagaimana menurut Tomlinson (1998: xi) dilakukan: sebelum penggunaan, saat penggunaan dan setelah penggunaan. Evaluasi dilakukan melibat- 
kan pakar karakter, pakar pendidikan, pakar desain grafis, dan pengguna bahan ajar (guru dan siswa).

Pertama, Komponen Kelayakan Isi. Berdasarkan analisis isi cerita rakyat Bengkulu ditemukan berbagai penjelasan berbagai perilaku yang menjadikan karakter tokoh. Perilaku tokoh yang dipaparkan dalam cerita tidak hanya perilaku tokoh yang baik-baik saja, tapi juga perilaku tokoh yang jahat, umpamanya tokoh religius, penolong, pemaaf, penyayang dan pendendam. Dampak setiap perilaku tokoh dipaparkan dengan jelas sehingga mudah dipahami selanjutnya layak dan dapat digunakan untuk acuan berperilaku atau sebagai sarana pendidikan. Sehubungan dengan kelayakan isi cerita rakyat hasil penelitian Morgan (2013) menyimpulkan bahwa penduduk Chewa di Zambia menggunakan cerita rakyat untuk sebagai instrumen dalam pembelajaran. Cerita rakyat digunakan untuk mempengaruhi pikiran para pemudanya. Sedangkan penelitian Tyra (2007) menyatakan banyak guru menggunakan sastra anak untuk membangun pengetahuan dasar anak dan untuk menggugah rasa ingin tahu anak. Sastra anak selalu digunaan untuk mengajarkan pendidikan karakter. Pendidikan karakter merupakan aspek penting yang harus dipelajari anakanak, karena mengajarkan mereka tentang perbedaan sosial dan pelajaran tentang moral.

Latihan-latihan dalam bahan ajar tampaknya belum menuntut kompetensi berpikir tingkat tinggi. Latihan-latihan untuk kelas 4-6 seharusnya dirancang kompetensi dari tingkatan C4 sampai dengan C6. Dalam Kemendikbud Dirjenpendas (2014: 11) dijelaskan berdasarkan hasil studi internasional untuk membaca lebih dari 95\% peserta didik di SD kelas IV hanya mampu mencapai level menengah. Hal ini disebabkan soal-soal yang digunakan untuk mengukur kemampuan siswa belum dirancang sampai pada latihan-latihan yang mampu mencapai level tinggi dan advance.

Kedua, komponen kebahasaan sangat penting dalam meningkatkan kualitas pemahaman bacaan yang berkaitan dengan kemampuan mengerjakan latihan-latihan dari bacaan. Oleh sebab itu suatu bacaan sebaiknya disesuaikan dengan kemampuan perkembangan bahasa siswa SD. Kalimatkalimat yang digunakan dalam bahasa siswa siswa SD adalah kalimat sederhana. Daryanto (2013: 48) menyatakan kalimat dalam bahan ajar sebaiknya kalimat tunggal, pendek-pendek tidak beranak cucu. Kalimat-kalimat disusun secara logis, sehingga membentuk satu kesatuan yang utuh dari sebuah ide membentuk paragraf.

Ketiga, bahan ajar Mulok adalah bahan ajar yang berkaitan dengan bahasa. Jadi untuk meningkatkan keterampilan berbahasa siswa, maka susunan materi sesuai komponen keterampilan berbahasa yakni: menyimak, membaca, berbicara, menulis. Tarigan (2015: 1) menyatakan keterampilan berbahasa mencakup mencakup keterampilan: 1) menyimak, 2) berbicara, 3) membaca, dan 4) menulis. Selain komponen keterampilan berbahasa untuk memperkaya kosa kata siswa dalam bahasa daerah maka ditambah komponen kosa kata.

Cerita sebagai bahan bacaan dilengkapi satu gambar yang memvisualkan bagian isi cerita. Setiap sub judul juga dilengkapi gambar yang mempertegas sub judul. Gambar diletakkan dalam bagian teks cerita. Sitepu (2012: 135) mengatakan ilustrasi yang diletakkan terpisah dari teks yang terkaitakan membingungkan dan menyu- 
litkan siswa belajar.

Cerita rakyat sebagai bagian budaya cenderung hampir punah, sedangkan cerita rakyat perlu dipahami, karena cerita mengemas berbagai manfaat yang dapat dijadikan sebagai media pendidikan. Oleh sebab itu perlu disajikan agar tidak punah. Penyajian cerita rakyat tidak hanya dijadikan bahan ajar. Dorji (2007) menjelaskan untuk menghindari legenda lokal dari kepunahan dan membuat orang memiliki pemahaman yang lebih luas dan dinamis legenda lokal direkomendasikan menggunakan teknologi digital terbaru.

Keempat, bahan ajar setiap halaman dilengkapi ilustrasi. Setiap halaman secara konsisten menggunakan beberapa warna, maksimal menggunakan empat warna. Sitepu (2012:152) mengatakan warna dapat menambah daya tarik dan membangkitkan motivasi untuk mengamati ilustrasi dan membaca teks penjelasannya. Bassano (2015:34) menyebutkan "dampak warna melebihi respon visual". Selain itu Campbell (2002:127) menyebutkan "Ketertarikan dan kegembiraan dalam materi-materi belajar dapat dimunculkan dengan mengubah visual warna, bentuk dan gambar. Warna merupakan komponen pemikiran visual yang penting. Warna membedakan ide, membimbing perhatian, dan memperkuat ingatan". Suroso (2010:92) menyebutkan "Gunakan warna karena akan meningkatkan memori, menyenangkan mata dan merangsang proses selaput otak sebelah kanan". Sedangkan Bassano (2015:20) menyatakan "Warna sangat bagus untuk merangsang sel otak, yang lain dapat memperkuat intuisi dan lainnya menimbulkan kedamaian serta ketenangan pikiran." Hasil penelitian Stokes (2012) menyimpulkan elemen visual dalam pembelajaran dapat memberikan hasil yang positif.

Kelima, data dari hasil penelitian berkaitan dengan pembelajaran yang menggunakan bahan ajar Mulok tampak dari peroleh nilai rata-rata siswa yang mencapai nilai KKM yakni 65, dan siswa sudah mencapai rata-rata siswa adalah 71.74 dibandingkan dengan nilai siswa menggunakan bahan ajar lain. Berdasarkan observasi selama pembelajaran siswa sangat suka dengan bahan ajar Mulok yang dikemas dengan berbagai ilustrasi bacaan maupun ilustrasi latihan-latihan. Ketertarikan siswa terhadap bahan ajar tidak lepas dari peroses produk bahan ajar yang berawal dari kebutuhan siswa. Materi pokok bahan ajar terkait dengan cerita yang pernah mereka dengar. Ghazali (2010: 38) menyatakan konteks pembelajaran yang efektif adalah penggabungan budaya ke dalam pengajaran. Namun hasil penelitian Joshua (2013) menyimpulkan untuk memperomosikan moralitas dan akibat perilaku anti sosial dongeng harus terus ada dan diproduksi menjadi film.

Fungsi dari adanya muatan lokal yaitu untuk memperluas pengetahuan. Sedangkan pentingnya ilustrasi dalam bahan ajar Muslich (2010: 306) menyatakan ilustrasi merupakan bagian yang menjadi daya tarik awal dari buku dan dapat memperjelas materi.

\section{SIMPULAN}

Berdasarkan hasil dan pembahasa penelitian dapat disimpulkan sebagai berikut. Pertama, berdasarkan penialain pakar dan penggunana dinyatakan bahwa model bahan ajar yang dikembangkan memenuhi kriteria kelayakan untuk digunakan dalam pembelajaran Mulok. Penilaian kriteria kelayakan mencakup empat komponen, 
yakni (a) isi, (b) bahasa, (c) penyajian, dan (d) kegrafikan dengan persentasei= ratarata sebesar 79,9\%.

Kedua, uji efektivitas diperoleh dari nilai hasil uji coba lapangan dengan pedoman kriteria ketuntasan minimal (KKM) mata pelajaran Mulok, yakni 65. Nilai hasil uji coba lapangan mencapai rata-rata 71.74 dengan ketuntasan sekolah klasikal mata pelajaran Mulok adalah 65. Capaian nilai rata-rata siswa yang lebih tinggi dari nilai menunjukkan bahwa efektivitas model bahan ajar yang dkembangkan dapat tercapai, sehingga layak untuk digunakan dalam proses pembelajaran Mulok.

Ketiga, dalam penyusuan bahan ajar pembelajaran Mulok harus memperhatikan: (a) isi dan tema cerita rakyat, (b) tidak semua cerita rakyat sesuai untuk bahan ajar, dan (c) ilustrasi yang dimuat dalam bahan ajar harus mampu menciptakan pembelajaran lebih menarik. Optimalisasi pemanfaatan cerita rakyat dalam pembelajaran Mulok diharapakan dapat meningkatkan perkembangan budaya lokal dan mewarikannya kepada generasi muda.

\section{UCAPAN TERIMA KASIH}

Ucapan terima kasih disampaikan kepada teman sejawat yang telah memberi masukan dalam proses penelitian. Ucapan terima kasih disampaikan juga kepada reviewer yang telah memberi masukan untuk perbaikan artikel ini.

\section{DAFTAR PUSTAKA}

Abidin, Yunus. 2012. Pembelajaran Bahasa Berbasis Pendidikan Karakter. Bandung: Refika Aditama.

Banda, Dennis \& W.J. Morgan. 2013. "Folklore as an Instrumen of Education Among the Chewa People of Zambia."
Int Rev Educ. DOI 10.1007/s11159-0139353-5. 22 May 2013.

Bassano, Mary. dkk. 2015. Terapi Musik \& Warna. Cara Dasyat Hidup Lebih Sehat dan Bahagia. Yogjakarta: Araska.

Borg, Walter R. Meredith D. Gall. 1983. Fourth Edition Educational Research An Introduction. New York: Longman.

Cambell, Linda. dkk. 2002. Multiple Intelligences, Metode Terbaru Melesatkan Kecerdasan. (Alih Bahasa: Tim Inisiasi). Depok: Inisiasi Pers.

Daryanto. 2013. Menyusun Modul Bahan Ajaruntuk Persiapan Guru dalam Mengajar. Yogyakarta: Gava Media

Depdiknas. 2008. Panduan Pengembangan Bahan Ajar. Jakarta: Depdiknas.

Dorji, Tshering Cigay. "Preserving our Folktales, Myths and Legends in the Digital Era. Journal of Bhutan Studies." 2007.

Endaswara, Suwardi. 2013. Pendidikan Karakter dalam Folkolor Konsep, Bentuk, dan Model. Yogyakarta. Rumah Suluh.

Ghazali, Syukur. 2010. Pembelajaran Keterampilan Berbahasa dengan Pendekatan Komunikatif-Interaktif. Bandung: Refika Aditama.

Gopal, Ravi. "Indigenous Environmental Knowledge in Formal Education". Jurnal Penyelidikan MPBL, Jilid 6. 2005.

Hikmah, Noor \& Marliana. Dinamika Ilmu, "Pendidikan Berbasis Muatan Lokal sebagai Sub Komponen Kurikulum" Marliana dan Noor Hikmah." Vol. 13. No. 1, hlm 105-119, Juni 2013.

Joshua, Usman. et.al. "Folktales as Material Resources for Movie Production in Selected Nollywood Movies." Academic Journals. Vol. 4 (5). pp. 236-241. July. 2013.

Kemendikbud. 2014. Panduan Teknis Pengembangan Muatan Lokal di Sekolah Dasar. 
Jakarta: Dirjenpendas.

Kemendikbud Dirjendikdas. 2014. Kurikulum 2013 untuk Sekolah Dasar (SD). Jakarta: Dirjendikdas.

Kemendikbud Dirjendikdas. 2015. Panduan Penilaian untuk Sekolah Dasar (SD). Jakarta: Dirjendikdas.

Mukhyati \& Siti Sriyati. 2015 Pengembangan Bahan Ajar Perubahan Lingkungan Berbasis Realitas Lokal dan Literasi Lingkungan. Proceding, Seminar Nasional. Surakarta: FKIP UNS.

Muktadir, Abdul. Oktober. "Pengembangan Model Mata Pelajaran Mulok Berbasis Kearifan Lokal untuk Meningkatkan Karakter Siswa di SD Provinsi Bengkulu". Jurnal Pendidikan Karakter. Tahun IV, No. 3. H. 318-331. Tahun 2014.

Peraturan Menteri Pendidikan dan Kebudayaan Indonesia Nomor 79 Tahun 2014 tentang Muatan Lokal Kurikulum 2013

Muslich, Masnur. 2010. Text Book Writing. Jogjakarta: Ar-Ruzz Media.

Tyra, Courttney. "Bringing Books to Life:
Teaching Character Education through Children's Literature." Rising Tide. Volume 5.

Purwanti, Elly. Jurnal Pemiiran dan Pengembangan SD, "Peningkatan Kemampuan Guru Sekolah Dasar Muhammadiyah dalam Pengembangan Kurikulum Muatan Lokal." Jilid 1, Nomor 1, hlm. 15-21, April 2013,

Sitepu, B.P. 2012. Penulisan Buku Teks Pelajaran. Bandung: Remaja Rosdakarya.

Stokes, Suzanne. Elektronic Journal for the Integration of Technology in Education. "Visual Literacy in Teaching and Learning: A Literature Perspective." Vol. 1. No. 1. H. 10-19. Tahun 2012.

Suroso, 2010. Smart Brain, Metode Menghafal Cepat dan Meningkatkan Ketajaman Memori. Surabaya: SIC.

Tarigan, Djago. 2015. Membaca Sebagai Suatu Keterampilan Berbahasa. Bandung: Angkasa.

Tomlinson, Brian. (ed.). Materials Development in Language Teaching. Cambridge: Cambridge University Press, 1998. 